\title{
Extraabdominal desmoid tumors
}

\author{
Kurtus Dafford, M.D., ${ }^{1}$ Daniel Kim, M.D., ${ }^{2}$ Adriane Nelson, M.D., ${ }^{3}$ \\ AND DAVID KLINE, M.D. ${ }^{4}$ \\ ${ }^{1}$ Department of Neurosurgery, Tulane University Medical Center, New Orleans; ${ }^{2}$ Department \\ of Neurosurgery, Ochsner Clinic Foundation, New Orleans; and ${ }^{3}$ Department of Pathology \\ and ${ }^{4}$ Department of Neurosurgery, Louisiana State University Health Sciences Center, \\ New Orleans, Louisiana
}

\begin{abstract}
Object. Desmoid tumors are fibrous, slow-growing, nonmalignant tumors with a low potential for metastasis. These lesions show a high propensity for infiltrative growth with local invasion.

Methods. The authors undertook a retrospective study of 15 desmoid tumors in 11 women and four men (ranging in age from 32 to 67 years; median 48 years) treated at their institution. This study included further resection for recurrent tumors in nine of 15 patients $(60 \%)$.

Results. There were 13 patients (86\%) with brachial plexus lesions, one patient (7\%) with a lumbar plexus lesion, and one (7\%) with a peroneal nerve lesion. There was a female predominance in the study group of 2.75:1. Four patients (27\%) reported improvement in pain status, six (40\%) reported no change from their preoperative pain levels, and five (33\%) reported worsened pain symptoms. There was tumor recurrence in two patients (13\%) leading to further surgical intervention.

Conclusions. This case series included many recurrent desmoid tumors of the brachial plexus. Most of these lesions were relatively large tumors, predominantly involved with the plexal elements adding to the challenge of the resection. Currently, function-sparing excision is considered the optimal treatment for desmoid tumors arising in extraabdominal sites. Adjunctive radiation or brachytherapy is reserved for a patient with further recurrence in whom resection would be disfiguring or in whom the disease is more refractory.
\end{abstract}

KEY WORDS • desmoid tumor • extraabdominal • fibromatosis • retrospective review

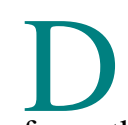

ESMOID TUMORS ARE rare, benign slow-growing neoplasms with a high propensity for aggressive invasion of local structures. These tumors arise from the facial and musculoaponeurotic tissues of the body, ${ }^{1,5,11}$ and are known to occur in intraabdominal, abdominal, and extraabdominal locations. Müller ${ }^{12}$ first coined the term "desmoid" in 1838 to describe the banded or tendonlike appearance of the tumor. ${ }^{14}$ Over the years, many terms have been used to describe this tumor, including: "well-differentiated nonmetastasizing fibrosarcoma," "fibrosarcoma," "Grade I fibrosarcoma," and "aggressive fibromatosis.",, 17

Pathologically, desmoid tumors have a benign microscopic appearance. However, this tumor is well-known for local infiltration and recurrence after resection. Currently, no markers have been identified to predict either the aggressive nature or rate of local recurrence after treatment,

Abbreviation used in this paper: GTR = gross-total resection. which poses a particular problem in the treatment lesions of the head and neck. The lesion's proximity to vital neurovascular structures compromises the surgeon's ability to obtain wide excision margins. Radiation or chemotherapeutic treatment options as adjuncts to excision have been described. $5,6,11,14,16,17,20$

We retrospectively review 15 cases of desmoid tumors treated at our facilities. The diagnostic imaging characteristics, histopathological findings, surgical management, and eventual clinical outcomes are discussed.

\section{Clinical Material and Methods}

This is a retrospective review of 15 patients who presented to our institution for the surgical management of desmoid tumors. The clinical diagnosis was confirmed with histological specimens taken during each surgical procedure. Particular attention was given to location of the lesion, previous treatment, surgical approach, and clinical outcomes. Many patients presented with large or recurrent 
TABLE 1

Clinical data in 15 patients with desmoid tumors who underwent surgery at the Louisiana State University Health Sciences Center

\begin{tabular}{|c|c|c|c|c|c|c|c|}
\hline $\begin{array}{l}\text { Age (yrs), } \\
\text { Sex }\end{array}$ & $\begin{array}{l}\text { Tumor } \\
\text { Location }\end{array}$ & $\begin{array}{c}\text { Prior Treatment } \\
\text { (no. of recurrences) }\end{array}$ & $\begin{array}{c}\text { Preop } \\
\text { Symptoms }\end{array}$ & $\begin{array}{l}\text { Surgical } \\
\text { Approach }\end{array}$ & $\begin{array}{l}\text { Extent of } \\
\text { Resection }\end{array}$ & Postop Status & $\begin{array}{l}\text { Follow-Up } \\
\quad(\operatorname{mos})\end{array}$ \\
\hline $48, \mathrm{~F}$ & brachial plexus & biopsy (2) & mass, pain & supraclavicular & subtotal & $\begin{array}{l}\text { unchanged weakness, } \\
\text { pain improved }\end{array}$ & 42 \\
\hline $54, \mathrm{~F}$ & brachial plexus & biopsy (1) & mass, pain & posterior subscapular & gross-total & $\begin{array}{l}\text { slight worse weakness, } \\
\text { pain improved }\end{array}$ & 56 \\
\hline $62, \mathrm{M}$ & brachial plexus & biopsy (2) & mass, pain, weakness & supra/infraclavicular & subtotal & $\begin{array}{l}\text { slightly worse weakness, } \\
\text { pain improved }\end{array}$ & 46 \\
\hline $32, \mathrm{~F}$ & brachial plexus & biopsy (1) & mass, weakness & supraclavicular & total & same preop function & 64 \\
\hline $43, \mathrm{~F}$ & axilla & & mass, paresthesia & infraclavicular & total & same function, pain better & 38 \\
\hline $46, \mathrm{M}$ & brachial plexus & biopsy (2) & mass, weakness, pain & supra/infraclavicular & subtotal & same function & 56 \\
\hline $39, \mathrm{~F}$ & lumbar plexus & (1) & mass, pain & retroperitoneal & subtotal & same function & 36 \\
\hline $51, \mathrm{~F}$ & brachial plexus & (1) & mass, pain & supraclavicular & subtotal & slightly worse & 34 \\
\hline $48, \mathrm{~F}$ & peroneal nerve & (1) & mass, pain & local resection & total & slightly weakness & 28 \\
\hline $67, \mathrm{~F}$ & brachial plexus & biopsy & mass, pain & supraclavicular & total & unchanged pain, weakness & 27 \\
\hline $58, \mathrm{M}$ & brachial plexus & biopsy & mass & supraclavicular & total & $\begin{array}{l}\text { worsened weakness, } \\
\text { tumor recurrence }\end{array}$ & 58 \\
\hline $56, \mathrm{~F}$ & axilla & (1) & mass, pain, weakness & infraclavicular & subtotal & pain, no weakness & 92 \\
\hline $37, \mathrm{~F}$ & brachial plexus & biopsy & mass, pain & supraclavicular & total & slightly worse & 24 \\
\hline $58, \mathrm{~F}$ & axilla & unknown & mass, pain & infraclavicular & subtotal & $\begin{array}{l}\text { tumor, underwent } \\
\text { amputation }\end{array}$ & 116 \\
\hline $46, \mathrm{M}$ & brachial plexus & biopsy & mass, pain & supraclavicular & total & increased pain \& weakness & 18 \\
\hline
\end{tabular}

lesions closely invested with plexal elements. Patient follow-up varied from 18 to 116 months (mean 49 months).

\section{Results}

The clinical data of the patients is outlined in Table 1. Eleven women and four men were included in our series, ranging in age from 32 to 67 years (median 48 years). Thirteen patients presented with tumors of the brachial plexus. One patient presented with a tumor of the lumbar plexus, and one patient presented with a tumor of the perneal nerve. The most common presenting symptoms were the presence of a palpable mass and local pain. Ten patients presented with recurrent tumors after prior resection at an outside facility, including three patients who had undergone more than one prior resection of the primary lesion. Four patients presented for treatment after biopsy sampling alone, and in two patients it was unknown whether they had previously undergone treatment or biop- sy. Seven patients underwent resection via the supraclavicular approach, three patients via an infraclavicular approach, and in an additional three patients a combined supra- and infraclavicular approach was used. One patient was treated via a posterior subscapular approach to the lesion. The lumbar plexus tumor was resected using a retroperitoneal approach, and the patient with peroneal nerve involvement underwent local resection of the mass only. Eight patients underwent GTR or total resection, and seven underwent subtotal resection.

Postoperatively, four patients reported improvement in their pain status. Six patients reported no change in their level of preoperative pain postoperatively. Five patients noted an increase in their pain postoperatively. One patient reported improvement of weakness postoperatively, and one patient reported no weakness pre- or postoperatively. Twelve patients noted no improvement in their weakness from preoperative levels, and six of these patients reported their weakness to be slightly worse postop-

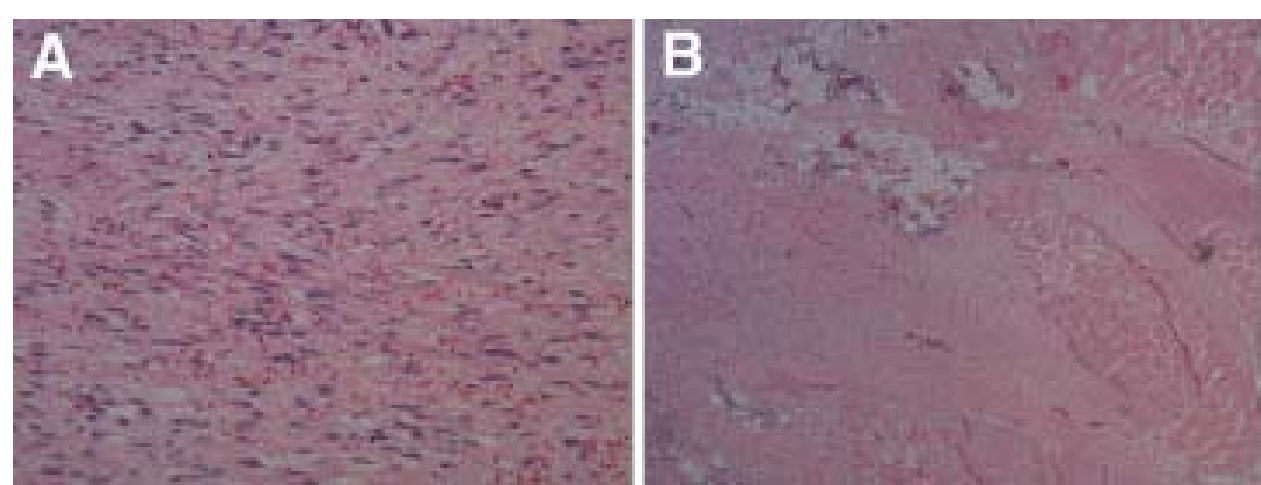

FIG. 1. Photomicrographs of demoid tumor tissue samples obtained in a 46-year-old man. A: Key diagnostic features of desmoid tumor are relatively bland spindle cells in an abundant collagenous matrix and extravasated red blood cells .B: Periphery of desmoid tumor showing infiltration into adipose tissue and muscle. $\mathrm{H} \& \mathrm{E}$, original magnification $\times$ $200(\mathrm{~A})$ and $\times 20(\mathrm{~B})$. 


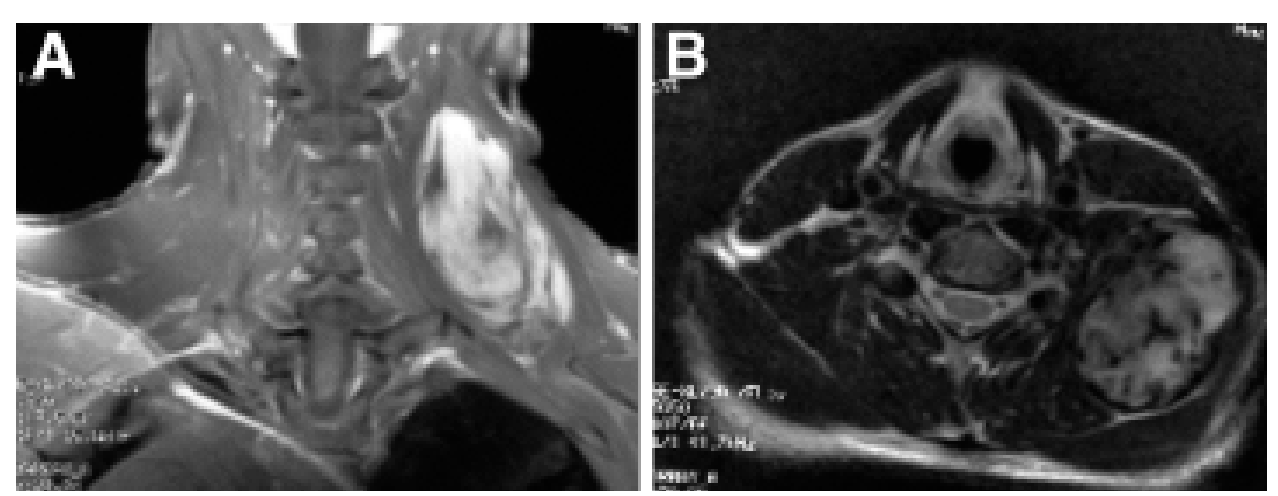

FIG. 2. Magnetic resonance images of a desmoid tumor obtained in the same patient as in Fig. 1. A: Coronal T1weighted contrast-enhanced image. B: Axial T2-weighted image.

eratively. Two patients reported tumor recurrence, with amputation in one patient.

\section{Discussion}

MacFarlane ${ }^{9}$ provided the first description of aggressive fibromatosis in the literature in 1832. Müller is credited with the description, coining the term "desmoid" in 1838 to describe the tendonlike band appearance of these tumors. ${ }^{14}$ Mackenzie further described these lesions as an infiltrating fibroblastic proliferation without any inflammatory response and no features of neoplasia. ${ }^{10,17}$ The rarity of these tumors is reflected in the case series available in the literature. Fasching and colleagues ${ }^{3}$ (48 cases), Conley et $\mathrm{al.}^{2}$ (40 cases), Weiss and Goldblum ${ }^{25}$ (35 cases), Wang et $\mathrm{al}^{21}$ (24 cases), and Hoos et al. ${ }^{5}$ (21 cases) account for the majority of cases of desmoid tumor in case series. Most other studies included fewer than 10 cases. ${ }^{1,20-22}$

Desmoid tumors were noted by Pack and Ehrlich ${ }^{15}$ to account for $0.03 \%$ of all neoplasms. ${ }^{6}$ They are generally thought to comprise fewer than $3 \%$ of all soft tissue neoplasms. Other authors have reported an incidence as high as 3.5 to $3.7 \% .^{6,8,13}$ Extraabdominal desmoid tumors comprise approximately one-third of all reported cases, with up to $15 \%$ of these tumors being reported to arise in the head and neck. The most common site of occurrence in the head and neck includes $80 \%$ in the anterolateral aspect of the neck. ${ }^{24}$ There is some question regarding the real incidence of these tumors, due to their being labeled as low-grade fibrosarcomas by some pathologists.

Histologically, these lesions are described as well-differentiated fibroblasts or myofibroblasts in an associated abundant collagen matrix (Fig. 1), with scanty or absent mitotic activity or other atypical cytological features. ${ }^{1,5,17}$ Differentiation of this tumor type from fibrosarcoma is essential, as desmoid tumors do not possess the tendency for metastasis. However, their local invasion along facial planes is ubiquitous and often involves nearby vascular and/or neural structures. There is reported involvement of the epineurium without further invasion to deeper neural structures. ${ }^{7,8}$ Although considered well-circumscribed, no capsular formation has been noted with this lesion, which further differentiates it from fibrosarcoma. Recently, Seinfeld et al. ${ }^{19}$ have proposed the assessment of the $c$-KIT mutational status of desmoid tumors.

Radiological evaluation of this lesion has relied on computed tomography and magnetic resonance imaging scans. Magnetic resonance imaging is considered superior in evaluating of the pattern of tumor growth as well as the involvement of nearby structures. Desmoid tumors of the deep structures are described as having a fusiform appearance, with subcutaneous tumors being more stellate in nature..$^{23}$ On computed tomography scans, the lesion appears hyperattenuated with significant enhancement after the application of contrast material. ${ }^{1}$ Magnetic resonance imaging characteristics include a lesion that is hypointense to isointense relative to muscle on T1-weighted imaging, and with a signal intensity similar to fat on T2weighted images ${ }^{23}$ (Fig. 2). It is considered essential for patients to undergo at least one of these two imaging modalities prior to excision of the lesion to demonstrate extent of the lesion and involvement of local structures. Imaging helps to provide optimal surgical planning, allowing the surgeon preoperatively to weigh the possibility of GTR versus subtotal resection.

Resection is aimed at as complete resection of the tumor load as possible, and is currently considered the mainstay of treatment. Biopsy sampling of these lesions can prove difficult, and most biopsy specimens are inconclusive for diagnosis. Furthermore, biopsy sampling exposes the patient to the risk of neurological injury - such injury may be due to associated nerves or fascicles spread over the surface of the tumor or adherent to the edges or periphery of the tumor. ${ }^{18}$ Most authors advocate a margin of 2 to $3 \mathrm{~cm}$ beyond the edges of palpable tumor to achieve local control. $7,8,11,21,22$ This recommendation is derived from the inability of the surgeon to clearly delineate the margins of the lesion during GTR due to the infiltrative properties of this tumor (Fig. 3). Control of local recurrence has been cited by some as related to the extent of a clear margin obtained when the mass is excised. Authors of other studies indicate that there are no predictive factors available to determine tumor recurrence rates, however. ${ }^{4-6,14,17}$ A local recurrence rate of 35 to $65 \%$ has been reported in some studies. Therefore, most authors advocate GTR only if vital structures can be spared. This is especially true in tumors of the head and neck region where total resection can lead to further refractory and disfiguring surgery after recurrence. Judicious resection of lesions in a manner that spares as much function as possible with close observation of recurrence is indicated. ${ }^{4,5}$

There is controversy in the literature concerning the use 


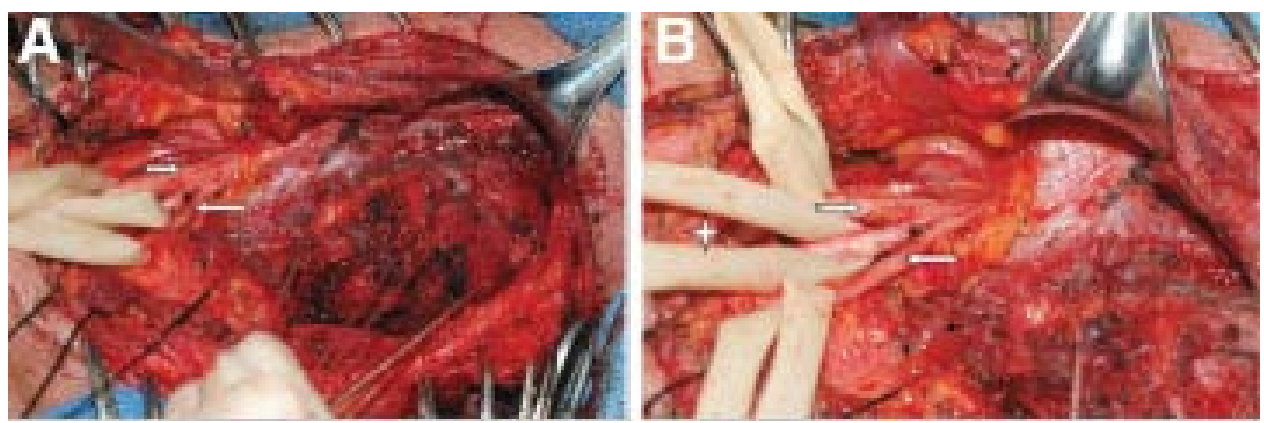

FIG. 3. Intraoperative photographs obtained in the same patient as in Figs. 1 and 2. A: View of the left supraclavicular desmoid tumor resection. B: View of the left supraclavicular approach demonstrating the resection bed with the desmoid tumor removed. Star = clavicle; notched arrow $=$ inferior trunk of the brachial plexus; block arrow = superior trunk of the brachial plexus; black arrows = divided posterior belly of the digastric muscle.

of primary or adjuvant radiation therapy to treat desmoid tumors. Wang and coworkers ${ }^{24}$ advise that further therapy after resection of the lesion is unnecessary in tumors with microscopically residual disease. In patients with recurrence, further excision is considered effective and achieves good results in the absence of other contraindications. ${ }^{16,24}$ Other authors have demonstrated the value of radiotherapy in the primary or adjunctive treatment of desmoid tumors, and recommend the use of low-dose radiation or interstitial brachytherapy as an adjunctive treatment after resection or primary treatment of smaller lesions to avoid disfiguring or debilitating surgery. ${ }^{6,14}$ When used, the radiation dose fell within the range of 45 to 65 Gy. ${ }^{15,6,17}$ Kiel and $\mathrm{Suit}^{6}$ noted that complication rates after radiotherapy can be minimized if careful attention is given to a technique including secondary field shaping and reducing field techniques. Most authors would agree and recommend further treatment in the setting of known positive resection margins with infiltrative disease, as there is some evidence of decreased local recurrence. However, it should be noted that complete regression of tumor might not be seen for up to 2 years after irradiation in primarily treated tumors or in those with residual tumor load.

Other treatment modalities have included traditional cytotoxic chemotherapeutic agents, hormonal therapy, nonsteroidal antiinflammatory drug therapy, vitamin K, warfarin, and vitamin C. ${ }^{1,11}$ Systemic therapy with doxorubicin has been the treatment of choice in most chemotherapeutic regimes. ${ }^{11}$ The potential benefit in the use of such systemic therapy must be weighed against the morbidity associated with these regimes. Some authors noted an increase in the number of estrogen receptors and antiestrogen binding sites in these tumors, and the use of tamoxifen has been recommended. ${ }^{8}$ Further investigation into the $c$-KIT gene has been proposed, which would determine response to the imatinib mesylate therapy that is used in other gastrointestinal stromal tumors. ${ }^{19}$ No case series has included a large enough sample size to adequately demonstrate the benefits of any of these pharmacological therapies in the treatment of desmoid tumors.

\section{Conclusions}

Based on this series of large and often-reoperated tumors and a review of the literature, a number of conclu- sions can be drawn. Desmoid tumors are slow-growing, fibrous, nonmalignant lesions with a low propensity for metastasis. These lesions are recognized as having a high incidence of infiltration into surrounding structures with invasion into local structures. Adequate imaging studies should be obtained to assist the surgeon in planning for en bloc resection when possible. If the lesion cannot be removed with a surrounding cuff of normal tissue, functionsparing surgical intervention is still considered the treatment of choice. Residual tumor mass may be treated with radiotherapy or brachytherapy in the range of 4500 to $6500 \mathrm{cGy}$, but the use of this treatment should be balanced against radiation morbidity. Long-term follow-up with imaging studies is needed to determine tumor recurrence.

\section{References}

1. Abdelkader M, Riad M, Williams A: Aggressive fibromatosis of the head and neck (desmoid tumors). J Laryngol Otol 115:772-776, 2001

2. Conley J, Healey WV, Stout AP: Fibromatosis of the head and neck. Am J Surg 112:609-614, 1966

3. Fasching MC, Saleh J, Woods JE: Desmoid tumors of the head and neck. Am J Surg 156:327-331, 1988

4. Gaposchkin CG, Bilsky MH, Ginsberg R, Brennan MF: Function-sparing surgery for desmoid tumors and other lowgrade fibrosarcomas involving the brachial plexus. Neurosurgery 42: 1297-1303, 1998

5. Hoos A, Lewis JJ, Urist MJ, Shaha AR, Hawkins WG, Shah JP, et al: Desmoid tumors of the head and neck-a clinical study of a rare entity. Head Neck 22:814-821, 2000

6. Kiel KD, Suit HD: Radiation therapy in the treatment of aggressive fibromatoses (desmoid tumors). Cancer 54:2051-2055, 1984

7. Kim DH, Murovic JA, Tiel RL, Kline DG: Operative outcomes of 546 Louisiana State University Health Sciences Center peripheral nerve tumors. Neurosurg Clin N Am 15:177-192, 2004

8. Kim DH, Murovic JA, Tiel RL, Moes G, Kline DG: A series of 146 peripheral non-neural sheath nerve tumors: 30-year experience at Louisiana State University Health Sciences Center. J Neurosurg 102:256-266, 2005

9. MacFarlane J: Clinical Reports of the Surgical Practice of the Glasgow Royal Infirmary. Glasgow: D. Robertson, 1832

10. Mackenzie DH: The fibromatoses: a clinicopathological concept. Br Med J 4:277-281, 1972

11. Merchant NB, Lewis JJ, Woodruff JM, Leung DH, Brennan MF: Extremity and trunk desmoid tumors: a multifactorial analysis of outcome. Cancer 86:2045-2052, 1999 
12. Müller, J: Ueber den fenern Bau und die Formen der Krankhaften Geschwülste. Berlin: G. Reimer, 1838

13. Myhre-Jensen O: A consecutive 7-year series of 1331 benign soft tissue tumors. Clinicopathologic data. Comparison with sarcomas. Acta Orthop Scand 52:287-293, 1981

14. Nuyttens JJ, Rust PF, Thomas CR Jr, Turrisi AT III: Surgery versus radiation therapy for patients with aggressive fibromatosis or desmoid tumors: a comparative review of 22 articles. Cancer 88: 1517-1523, 2000

15. Pack GT, Erlich HE: Neoplasms of the anterior abdominal wall with special consideration of desmoid tumors: experience with 391 cases and a collective review of the literature. Int Abstr Surg 79:177, 1944

16. Pignatti G, Barbanti-Brodano G, Ferrari D, Gherlinzoni F, Bertoni F, Bacchini P, et al: Extraabdominal desmoid tumor. A study of 83 cases. Clin Orthop Relat Res 373:207-213, 2000

17. Plukker JT, van Oort I, Vermey A, Molenaar I, Hoekstra HJ, Panders AK, et al: Aggressive fibromatosis (non-familial desmoid tumor): therapeutic problems and the role of adjuvant radiotherapy. Br J Surg 82:510-514, 1995

18. Press JM, Rayner SL, Philip M, Monga TN, Katz RT: Intraoperative monitoring of an unusual brachial plexus tumor. Arch Phys Med Rehabil 73:297-299, 1992

19. Seinfeld J, Kleinschmidt-Demasters BK, Tayal S, Lillehei KO: Desmoid-type fibromatoses involving the brachial plexus: treatment options and assessment of c-KIT mutational status. J Neurosurg 104:749-756, 2006
20. Sherman NE, Romsdahl M, Evans H, Zagars G, Oswald MJ: Desmoid tumors: a 20-year radiotherapy experience. Int J Radiat Oncol Biol Phys 19:37-40, 1990

21. Sikka RS, Vora M, Edwards TB, Szabo I, Walch G: Desmoid tumor of the subscapularis presenting as isolated loss of external rotation of the shoulder. A report of two cases. J Bone Joint Surg Am 86:159-164, 2004

22. Tse GM, Chan KF, Ahuja AT, King AD, Pang PC, To EW: Fibromatosis of the head and neck region. Otolaryngol Head Neck Surg 125:516-519, 2001

23. Vandevenne JE, De Schepper AM, De Beuckeleer L, Van Marck E, Aparisi F, Bloem JL, et al: New concepts in understanding evolution of desmoid tumors: MR imaging of 30 lesions. Eur Radiol 7:1013-1019, 1997

24. Wang CP, Chang YL, Ko JY, Cheng CH, Yeh CF, Lou PJ: Desmoid tumor of the head and neck. Head Neck 28: 1008-1013, 2006

25. Weiss SW, Goldblum JR (eds): Enzinger and Weiss's Soft Tissue Tumors, ed 4. St. Louis: Mosby, 2001

Manuscript submitted March 23, 2007.

Accepted May 10, 2007.

Address reprint requests to: Daniel Kim, M.D., Department of Neurosurgery, Ochsner Clinic Foundation, 1514 Jefferson Highway, New Orleans, Louisiana 70121. email: neurokimdaniel@ yahoo.com. 